\title{
Performance evaluation of the DCMD desalination process under bench scale and large scale module operating conditions
}

\author{
L. Francis, N. Ghaffour, A.S. Alsaadi, S.P. Nunes, G.L. Amy \\ Water Desalination and Reuse Center, King Abdullah University of Science and Technology (KAUST), \\ 23955-6900 Thuwal, Saudi Arabia, Tel. +966-28082180,Email: noreddine.ghaffour@kaust.edu.sa
}

\begin{abstract}
The flux performance of different hydrophobic microporous flat sheet commercial membranes made of poly tetrafluoroethylene (PTFE) and poly propylene (PP) was tested for Red Sea water desalination using the direct contact membrane distillation (DCMD) process, under bench scale (high $\Delta \mathrm{T}$ ) and large scale module (low $\Delta \mathrm{T}$ ) operating conditions. Membranes were characterized for their surface morphology, water contact angle, thickness, porosity, pore size and pore size distribution. The DCMD process performance was optimized using a locally designed and fabricated module aiming to maximize the flux at different levels of operating parameters, mainly feed water and coolant inlet temperatures at different temperature difference across the membrane $(\Delta T)$. Water vapor flux of $88.8 \mathrm{~kg} / \mathrm{m}^{2} \mathrm{~h}$ was obtained using a PTFE membrane at high $\Delta \mathrm{T}\left(60^{\circ} \mathrm{C}\right)$. In addition, the flux performance was compared to the first generation of a new locally synthesized and fabricated membrane made of a different class of polymer under the same conditions. A total salt rejection of $99.99 \%$ and boron rejection of $99.41 \%$ were achieved under the extreme operating conditions. On the other hand, a detailed water characterization revealed that low molecular weight non-ionic molecules ( $\mathrm{ppb}$ level) were transported with the water vapor molecules through the membrane structure. The membrane which provided the highest flux was then tested under large scale module operating conditions. The average flux of the latter study (low $\Delta \mathrm{T}$ ) was found to be eight times lower than that of the bench scale (high $\Delta \mathrm{T})$ operating conditions.
\end{abstract}

Keywords: Seawater desalination; DCMD flux; MD membranes; Rejection; Large scale module operating conditions. 


\section{Introduction and background}

In a time when the world demand for clean water cannot always be met by the available conventional energy sources, such as oil and gas, technologies which use renewable energy or waste heat for water desalination will fill an important niche. In arid regions like those of the Arabian Gulf Cooperation Council (GCC), the situation is the worst since the demand for fresh water is almost completely met by thermal-based distillation processes using fossil fuel as their main energy driver [1]. Membrane Distillation (MD) is considered as one of the technologies that is emerging as an attractive alternative desalination process. Details on the MD process have been widely reviewed [2-6]. It holds the potential of being an efficient and cost effective separation process that can utilize low-grade waste heat or renewable energy such as geothermal [7-9] or solar [10-14] energies, which are widely available in the region.

Compared to other conventional desalination processes such as Reverse Osmosis (RO), Multi Stage Flash (MSF) and Multi Effect Distillation (MED), MD has several unique advantages, which could make it the preferred technology in some niche applications. These include:

- MD can produce high water quality and is theoretically a total barrier for ions, macromolecules, colloids, cells, and other non-volatiles [15].

- It is suitable for remote locations (off grid) using renewable energy as it can operate at various loads [8-14], contrary to the conventional processes which require stable operation to maintain efficiency [16].

- It can operate at atmospheric pressure, as opposed to the high pressure required for RO process. Thus, no mechanical support is required.

- MD is not limited by either flooding at high rate [3], unloading at low rate, or by the foaming experienced in the MSF process. Furthermore, it is not highly affected by high feed water salinity which makes it a suitable process to treat desalination brines, especially thermal brines $[17,18]$.

MD is a thermally driven process that utilizes a hydrophobic, micro porous membrane as a contactor to achieve separation by liquid-vapor equilibrium. The feed solution, after being heated, is brought into contact with the membrane which allows only the vapor to go through the dry pores so that it condenses on the permeate side. This vapor is driven across the membrane by the difference in the partial water vapor pressure $(\Delta \mathrm{P})$ maintained at the two sides of the 
membrane. Four different MD configurations have been proposed [14]. The main difference in these configurations consists of the type of the condensing (cold side) design. Direct contact membrane distillation (DCMD) is the most studied configuration at the bench-scale. $\triangle \mathrm{P}$ is induced by the trans-membrane temperature difference $(\Delta \mathrm{T})$ established by maintaining a direct contact of an aqueous solution, colder than the feed solution, at the permeate side of the membrane. At the hot liquid/vapor interface, the volatile molecules evaporate and pass through the membrane and are condensed at the cold vapor/liquid interface.

Commercial membranes have been significantly improved since the development of the MD process and are now used in several recent pilot plant studies [10, 12, 19-23]. The important characteristics required for a good MD membrane such as excellent chemical resistance, good thermal stability, high liquid entry pressure (LEP), low thermal conductivity, high porosity, high hydrophobicity, and narrow pore size distribution have been reported extensively [3, 24-36]. However, there are still some issues that have not yet been clearly addressed, such as:

- Is the current reported MD flux limited by the membrane or by the process parameters and module design, or the low thermal efficiency of the system?

- Are the available commercial membranes good enough for scaling-up the MD process and, if not, what are the necessary improvements? In seawater desalination application, the reported bench-scale MD fluxes are quite high. However, most of these bench-scale studies do not reflect the reality of larger scale modules as they are mostly tested under high $\Delta \mathrm{T}$ with relatively high flow rates (temperature drop from each side of the membrane is not significant due to small membrane surface area), while the situation in large scale modules is completely different as the feed and coolant inlet temperatures decrease significantly throughout the module (temperature drop in each side of the membrane). In large scale modules, even at high feed and coolant inlet temperatures, $\Delta \mathrm{T}$ across the membrane is small, hence lower flux is expected. A more realistic scenario of large scale module operating conditions is described and discussed in Section 3.3.

The main potential challenges toward scaling-up the MD process; reduce the conductive losses in order to maintain the flux stability over time and minimize temperature polarization and avoid pore wetting; have been reported in detail [3, 37].

Khayet [3] and Alkhudhiri et al., [2] tabulated information on most of the commercial membranes used in MD studies. Most of the references identified in these studies used distilled 
water and $\mathrm{NaCl}$ solution as feed (synthetic seawater) in their experimental tests. Such feeds might not provide an accurate indication of the capability of the commercial membranes to desalinate seawater. However there are few reported works using real seawater as feed for MD [38-41], but the obtained flux performances were very low compared to synthetic seawater.

In this work, we partially answer the question on the expected satisfactory flux in MD systems by subjecting different PTFE and PP commercial membranes to real Red Sea water and compare their performance with the first generation of a new locally synthesized and prepared membrane made of fluorinated polytriazole [36]. The DCMD process was carried out using a locally fabricated module for different operating parameters, mainly feed and coolant inlet temperatures, in order to address some of the issues constraining MD scale-up. This study also includes a detailed feed and product water analysis and membrane characterization using advanced analytical equipment.

\section{Material and methods}

\subsection{MD membranes}

Different hydrophobic microporous PTFE and PP commercial membranes supplied by different manufacturers as well as a locally synthesized and fabricated fluorinated polytriazole membrane, made for MD application, were tested for desalting real Red Sea water using the DCMD process. Detailed commercial membrane characterization is presented in Section 3. Description of the characteristics and performance evaluation of the locally fabricated membrane tested for DCMD has been analyzed in detail and reported in previous work [36].

\subsection{Surface morphology of membranes}

Membranes were characterized for their surface morphology by using Scanning Electron Microscopy (SEM). Membrane samples were sputter coated using a Sputter Coater (EMITECH $\mathrm{K} 575 \mathrm{X}, \mathrm{UK}$ ) machine to coat a thin gold layer to make the film surface conductive. The surface morphology of all the membranes before and after the MD process was studied under field emission scanning electron microscopy (FE-SEM; Quanta 200 FEG System: FEI Co., USA). Energy Dispersive X-ray Spectrometry (EDX) analysis of the components found on the 
membrane surface after the DCMD process was also carried out using EDAX AMETEK precision instruments, UK.

\subsection{Feed water and MD product characterization and analysis}

Red Sea water collected from the SWRO commercial plant at the King Abdullah University of Science and Technology (KAUST) intake pipe (before pretreatment) [42] was used as feed for all DCMD experiments. Seawater was filtered through a $10 \mu \mathrm{m}$ filter in the lab to remove large suspended solids and used as MD feed without any additional pretreatment. Feed water and MD product characterization/analysis were performed using LC-OCD/OND (Liquid Chromatography with organic Carbon/Nitrogen detection) and ICP-MS (Inductively Coupled Plasma-Mass Spectroscopy).

\subsection{Bubble point, pore size pore size distribution and gas permeability of membranes}

A porometer (IB-FT Gm bH Porolux 1000, Germany) was used to determine the Mean Flow Pore size (MFP), First Bubble Point (FBP) and pore size distribution, by the wet-up/dry-up method with the analysis done using an Automated Capillary Flow Porometer system software. A $20 \mathrm{~mm}$ diameter sized membrane sample was mounted on the sample chamber of the porosimeter. The sample was fully wetted with Porefil (fluorinated hydrocarbon with surface

tension 16 dynes $\mathrm{cm}^{-1}$ ) and the chamber was sealed. Pure nitrogen was then allowed to flow into the chamber gradually. When the increased nitrogen pressure reached a point that overcame the capillary flow of the fluid within the largest pore, the bubble point was found. After determining the bubble point, the pressure was increased continuously and the nitrogen permeation rate was measured until all pores were empty of Porefil, and the sample was considered dry. Nitrogen pressure and permeation flow rates through the dry sample were also recorded. Based on the nitrogen flow rates through the wet and dry membranes, the pore size distribution was calculated. Gas permeability through the membranes was measured using the same set-up and procedure without wetting the membranes and by using nitrogen gas. Based on the gas flow rate through the membrane at constant pressure, the system calculates the mass transfer coefficient of each membrane.

\subsection{Membrane thickness, porosity, and water contact angle}


Membrane thickness was measured using a digital micrometer, DML 3032 from Digital Micrometers LTD, UK which has an accuracy of $0.005 \mathrm{~mm}$. The porosity of a membrane indicates the void fraction of the membrane (defined as the volume of the pores divided by the total volume of the membrane). Higher porosity membranes have a larger evaporation surface area contributing to a higher permeate flux and lower heat loss through conduction $[3,37,43]$.

Porosity $(\varepsilon)$ of the membranes was calculated as per the method illustrated by Palacio et al [44]. The membrane samples were cut into a known surface area and weighed accurately $\left(w_{1}\right)$ and the samples were impregnated in isopropyl alcohol and sonicated for 15 minutes to eliminate any trapped air in the membrane pores and kept overnight so that all the empty voids are assumed to be filled with the wetting liquid. Afterwards the fully impregnated membrane samples were removed from the isopropanol and, after excess liquid from the surface of the membranes was wiped, again weighed $\left(w_{2}\right)$. Pore volume $(V p)$ can be calculated by the ratio of the difference in the weight $\left(w_{2}-w_{1}\right)$ to the density of the wetting liquid $\left(\rho_{\text {liq }}\right)$ and the porosity $(\varepsilon)$ can be calculated by the ratio of the pore volume to the total geometric volume $\left(V_{t}\right)$ of the membrane sample. Porosity values are presented in Table 2.

$$
\begin{aligned}
& V p=\left(w_{2}-w_{1}\right) / \rho_{\text {liq }} \\
& \varepsilon=1-V_{m} / V_{t}
\end{aligned}
$$

where the membrane volume $V_{m}=V_{t}-V_{p}$

For flat sheet membrane samples with a surface area $\mathrm{S}$ and with a thickness $\delta, V_{t}$ is given by: $V_{t}=\mathrm{S} \delta$

An average of three samples from each membrane was measured and reported. All the membranes investigated in this study had uniform morphology across the active layer by assuming the fact that all the membranes have been fabricated by uniform stretching.

The hydrophobic nature of membranes was measured using a goniometer (Attension, KSV instruments $\mathrm{T} 301$, Finland) at room temperature $\left(25^{\circ} \mathrm{C}\right)$. An average of five measurements at different locations of the membrane was taken as the water contact angle.

\subsection{Experimental set-up and procedure}

Figure 1 illustrates a schematic diagram of the DCMD module and experimental set-up. A flat sheet membrane module with an active surface area of $25 \mathrm{~cm}^{2}$, with flow channel dimensions of $50 \mathrm{~mm} \times 50 \mathrm{~mm} \times 2 \mathrm{~mm}$, was designed and fabricated at the Water Desalination and Reuse 
Center (WDRC) at KAUST. A poly propylene mesh spacer has been used at both sides of the membrane as a support.

Figure 1: A schematic diagram of the DCMD module and experimental set-up.

In order to enhance the hydrodynamics and assure a uniform flow distribution inside the module and avoid flow channels, the feed solution enters the module made of poly methyl methacrylate material through feed holes along the width of the module enabling a complete distribution of water on the membrane surface and increasing the flow velocity to enhance the turbulence inside the module and to reduce the temperature polarization effect (feed side). All membranes were cut into a desired size to fit into the DCMD module and subjected to MD testing at different operating conditions using the lab scale MD setup. Red Sea water was preheated to desired temperatures and circulated through one side of the membrane, whereas the de-ionized (DI) water was circulated through the other side of the membrane simultaneously in a counter-current mode. Feed and permeate temperatures were controlled using a heater and chiller (thermo-regulators), respectively. Feed water concentration was kept constant by adding pure water to the feed tank in order to compensate the amount of distillate produced. Fresh seawater was used for each experiment. Permeate was measured using weight scale. The increase of the permeate tank weight was continuously monitored and recorded in the computer using LabView software. Pressure, temperature and flow rates before and after the module were continuously monitored on both feed and permeate sides. Salt concentrations of both permeate and feed solutions were continuously measured and monitored in the computer using conductivity meters (Oakton Eutech Instruments, Malaysia). The salt rejection $(S R)$ and water vapor flux $\left(J_{v}\right)$ were determined using the following equations:

$S R=\left(1-C_{p} / C_{f}\right) \cdot 100$

$J_{v}=m_{w} / A . t$

where $C_{p}$ and $C_{f}$ are the salt concentrations of permeate and feed solutions, respectively. $m_{w}$ is the weight of collected permeate, $\mathrm{A}$ is the effective membrane area and $t$ represents the time interval. The influence of feed water temperature ranging from a $40{ }^{\circ} \mathrm{C}$ to $80^{\circ} \mathrm{C}$ on water vapor flux was studied by maintaining a constant temperature on the permeate side at $20^{\circ} \mathrm{C}$. Similarly the influence of coolant temperature ranging from $10{ }^{\circ} \mathrm{C}$ to $30{ }^{\circ} \mathrm{C}$ on trans-membrane flux was also 
studied by keeping the feed solution temperature constant at $60{ }^{\circ} \mathrm{C}$. In order to investigate and discuss module scale-up issues, a set of experiments with constant $\Delta \mathrm{T}$ between the feed inlet and permeate inlet temperatures $\left(\Delta \mathrm{T}=10^{\circ} \mathrm{C}\right)$ was performed for feed and coolant inlet temperatures ranging from $40{ }^{\circ} \mathrm{C}$ to $70{ }^{\circ} \mathrm{C}$ and $30{ }^{\circ} \mathrm{C}$ to $60{ }^{\circ} \mathrm{C}$, respectively (Fig. 6, Table 1). Feed and coolant flow rates were kept constant at $1.5 \mathrm{~L} / \mathrm{min}$ (equivalent to cross-flow velocities of $0.25 \mathrm{~m} / \mathrm{s}$ ) for all experiments. Each experiment was conducted for four hours. In bench-scale experiments, the time to reach steady state depends more on the control system, mainly heating and cooling, rather than thermal stability within the small module which is achieved very fast. In our experiments, the steady state was quickly achieved by keeping the heater and cooler continuously running (in closed loops) even during membrane replacement.

Table 1: Feed and coolant inlet temperatures for experiments at $\Delta \mathrm{T}=10{ }^{\circ} \mathrm{C}$.

\section{Results and discussion}

\subsection{New membranes characterization and analysis}

Figure 2 shows the SEM images of various new hydrophobic microporous membranes used in this study. Detailed characterization of the locally fabricated polyazole membrane is reported in previous work [36].

Figure 2: SEM images of hydrophobic microporous membranes (a) PTFE (M1); (b) PP (M2); (c) PTFE (M3); (d) nonwoven support of PTFE (M1); and (e) scrim-backing support of PTFE (M3); (f) cross section of PTFE (M1).

Figures 2 (a), (b) and (c) represent the active layers of the PTFE (M1 and M3) and PP (M2) membranes. Figures 2 (d) and (e) represent the non-woven fabric support of PTFE (M1) and scrim backing support of PTFE (M3) membrane. Morphology reveals the porous structure of the membranes. PTFE active layers are knot-fibril structured whereas, the PP membrane does not have any support layer and SEM results showed a cylindrical pore structure compared to PTFE membranes. Figure 2 (f) shows the cross-sectional view of the PTFE (M1) membrane which 
clearly shows that the active layer is very thin compared to the support layer. This information could be useful to reduce the mass transfer resistance and to increase the heat transfer resistance during the DCMD process.

The pore size distribution of the different membranes is shown in Figure 3. The thickness, mean flow pore size (MFP), first bubble point (FBP), porosity and contact angle of the different membranes are also given in Table 2.

The PTFE (M3) membrane with scrim backing support has the thinnest layer among the various membranes with a thickness of $100 \mu \mathrm{m}$ and a porosity of $74 \%$ when compared with the thickness of $170 \mu \mathrm{m}$ and a porosity of $77 \%$ of the PTFE (M1) membrane with non-woven fabric support. On the other hand, the PP (M2) membrane has a thickness of $160 \mu \mathrm{m}$ and a porosity of $83 \%$ even without any support layer. The thickness of the membrane active layer plays a major role in the mass transport across the membrane during the MD process. MD performance increases with a decrease in the thickness of the membrane. The other important membrane characteristics for attaining better trans-membrane water vapor flux are optimal pore size and high porosity. High porosity enhances the mass transfer through the membrane due to the enhancement of water vapor transport coefficient as well as lowers the conductive heat flux. An increase in the mass transfer by reducing the thermal resistance of the membrane with the increase in the porosity of the membrane and an increase of the heat transfer with the decrease in the thickness of the active layer have been already reported by Zhang et al., [45]. SEM images (Figure 2) and narrow pore size distribution (Figure 3) of the investigated membranes reveals a uniform morphology across the active layer of the membrane. The effect of different support materials such as poly ester nonwoven and scrim backing supports on the DCMD performance has been investigated and reported by Adnan et al., [46]. These backing materials are helpful to fabricate very thin active membrane layers but at the same time they adversely affect DCMD performance by blocking some of the membrane pores in the active layer and by reducing the porosity. Despite these points, membrane support layers absorb a part of the sensible heat from the feed and increase temperature polarization.

Figure 3: Pore size distribution of hydrophobic microporous membranes (a) PTFE (M1); (b) PP (M2); and (c) PTFE (M3). 
Table 2: Characteristics of the various membranes.

Figure 3 shows a narrow pore size distribution of the various membranes. MFP obtained by the porosimeter is an indication of the average pore size of the membrane. FBP indicates the largest pore size of the membrane. The PTFE (M1) membrane has a FBP of $0.42 \mu \mathrm{m}$ and the smallest pore size of $0.23 \mu \mathrm{m}$. The other two membranes (M2 and M3) showed a two fold increase in the FBP and smallest pore size. The optimum pore size would be the largest pore size possible but small enough to prevent the entrance of water droplets through the membrane pore without any chance of pore wetting.

Mass transfer coefficients calculated for each membrane based on the gas permeability test are presented in Table 2. Mass transfer coefficient for PTFE M3 membrane showed a higher value of $0.0028 \mathrm{Kg} \cdot \mathrm{m}^{-2} \cdot \mathrm{hr}^{-1} \cdot \mathrm{Pa}^{-1}$, whereas those of M2 and M1 membranes showed much lower mass transfer coefficients equal to 0.001 and $0.0019 \mathrm{Kg} \cdot \mathrm{m}^{-2} \cdot \mathrm{hr}^{-1} \cdot \mathrm{Pa}^{-1}$, respectively. The higher the mass transfer coefficient, the greater is the water vapor flux. Both M1 and M3 membranes having very thin active layers showed higher mass transfer coefficients than M2 membrane with comparatively thicker active layer.

High hydrophobicity is another important characteristic of the membrane which leads to the minimum contact of water droplets with the membrane surface. An average of five water contact angle measurements of each membrane used in this study has been tabulated in Table 2 . The PTFE (M1) membrane has a water contact angle of $140^{\circ}$, whereas the other two membranes showed comparatively high values of contact angle close to $160^{\circ}$. These values indicate that the membranes are highly hydrophobic.

\subsection{Influence of feed and permeate temperatures on water vapor flux}

DCMD performance of various membranes with different characteristics, mainly materials, thickness, contact angle and pore size, was tested by varying the feed inlet temperature at constant permeate (coolant) inlet temperature, and vice versa, by maintaining constant flow rate (1.5 L/min) of both feed and permeate solutions. Figures 4 (a) and (b) show the water vapor flux profile for different feed inlet temperatures by maintaining constant permeate temperatures at 10 ${ }^{\circ} \mathrm{C}, 20{ }^{\circ} \mathrm{C}$ and $30{ }^{\circ} \mathrm{C}$ for PTFE (M3) and PP (M2) membranes, respectively. Experiments have 
been conducted more than three times for reproducibility, and the error bars measured during the experiments were observed to be less than $\pm 4 \%$, as shown in Figures 4 (a) and (b).

Figure 4: Water vapor flux profile versus feed water inlet temperature for different permeate inlet temperatures $\left(10^{\circ} \mathrm{C}, 20^{\circ} \mathrm{C}\right.$ and $\left.30^{\circ} \mathrm{C}\right)$ using (a) PTFE (M3) and (b) PP (M2) membranes.

Both membranes showed similar flux patterns, mainly an increase in water vapor flux with an increase in feed inlet temperature at constant feed and permeate velocities. Since both membranes have similar characteristics such as average pore size, smallest pore size, FBP and contact angle, as described in Table 2, comparable flux patterns were expected. $\Delta \mathrm{P}$ increases with the increase in the feed inlet temperature at constant permeate solution temperature. An increase in the feed inlet temperature from $50{ }^{\circ} \mathrm{C}$ to $60{ }^{\circ} \mathrm{C}$ results in an increase of flux from 23.9 $\mathrm{kg} / \mathrm{m}^{2} \mathrm{~h}$ to $41.2 \mathrm{~kg} / \mathrm{m}^{2} \mathrm{~h}$ only, whereas increasing the feed temperature from $60{ }^{\circ} \mathrm{C}$ to $70{ }^{\circ} \mathrm{C}$ and 70 ${ }^{\circ} \mathrm{C}$ to $80{ }^{\circ} \mathrm{C}$ enhanced the water vapor flux from $41.2 \mathrm{~kg} / \mathrm{m}^{2} \mathrm{~h}$ to $63.6 \mathrm{~kg} / \mathrm{m}^{2} \mathrm{~h}$ and from 63.6 $\mathrm{kg} / \mathrm{m}^{2} \mathrm{~h}$ to $88.8 \mathrm{~kg} / \mathrm{m}^{2} \mathrm{~h}$, respectively, while using the PTFE (M3) membrane. For a constant permeate inlet temperature of $20^{\circ} \mathrm{C}$, the increase of feed water temperature by increments of $10^{\circ} \mathrm{C}$ creates an average $\Delta \mathrm{P}$ of about $12 \mathrm{KPa}, 21 \mathrm{KPa}$ and $35 \mathrm{KPa}$, at feed inlet temperatures of $60{ }^{\circ} \mathrm{C}, 70{ }^{\circ} \mathrm{C}$, and $80{ }^{\circ} \mathrm{C}$, respectively, which increases the flux to $17.3 \mathrm{~kg} / \mathrm{m}^{2} \mathrm{~h}, 22.4 \mathrm{~kg} / \mathrm{m}^{2} \mathrm{~h}$ and $25.2 \mathrm{~kg} / \mathrm{m}^{2} \mathrm{~h}(72 \%, 166 \%$ and $272 \%)$, respectively. For practical reasons, mainly scaling control due to high temperature and concentration polarization, we did not investigate feed inlet temperatures higher than $80^{\circ} \mathrm{C}$ [47].

$\Delta \mathrm{P}$ also increases by decreasing permeate inlet temperature at constant feed inlet temperature and constant feed/permeate flow rates. This can clearly be observed from the flux profiles shown in Figures 4 (a) and (b). An increase of trans-membrane vapor pressure difference by varying permeate inlet temperature from $30{ }^{\circ} \mathrm{C}$ to $10{ }^{\circ} \mathrm{C}$, at constant feed inlet temperature, was inferred by observing an increase in the water vapor flux accordingly. However the effect of the increase was more significant at higher feed inlet temperatures due to higher evaporation. In fact, a $47 \%$ increase in flux was obtained by decreasing the permeate temperature from $30{ }^{\circ} \mathrm{C}$ to $10{ }^{\circ} \mathrm{C}(-20$ ${ }^{\circ} \mathrm{C}$ ) at feed temperature of $60{ }^{\circ} \mathrm{C}$, whereas a $166 \%$ increase in flux was observed while increasing the feed inlet temperature from $50{ }^{\circ} \mathrm{C}$ to $70^{\circ} \mathrm{C}\left(20^{\circ} \mathrm{C}\right)$ by keeping the permeate inlet 
temperature at $20^{\circ} \mathrm{C}$ for both PP (M2) and PTFE (M3) membranes, which confirms the discussion above.

Water vapor flux of $95.6 \mathrm{~kg} / \mathrm{m}^{2} \mathrm{~h}$ was obtained using the PTFE (M3) membrane at feed and permeate inlet temperatures of $80{ }^{\circ} \mathrm{C}$ and $10{ }^{\circ} \mathrm{C}$, respectively (Figure 4a). However, a longer time of operation is necessary to confirm the high performance of these membranes in terms of water vapor flux stability and rejection although it is not feasible to run a large MD module under these conditions, mainly at very high $\Delta \mathrm{T}$. A detailed explanation of this issue is presented in the next Section.

Figure 5: MD water vapor flux comparison between PTFE (M1), PP (M2), PTFE (M3) and the locally synthesized and fabricated polyazole electrospun membranes [36], at constant permeate inlet temperature of $20^{\circ} \mathrm{C}$.

Figure 5 shows a comparison of the different membrane performances in the DCMD process at various feed inlet temperatures. The water vapor fluxes produced by the PTFE (M1) and PP (M2) membranes were found to be $30 \%$ and $15 \%$ less than that of PTFE (M3) membrane, respectively. This can be attributed to the difference in the pore size, thickness and porosity between the membranes (Table 2). The pore size of the PTFE (M3) membrane was calculated to be twice the value of the PTFE (M1) membrane and the thickness of PTFE (M1) membrane was measured to be $70 \%$ higher than that of the PTFE (M3) membrane, which could cause the enhancement of mass transfer. On the other hand, the PTFE (M3) membrane gave higher flux than that of PP (M2) membrane probably due to lower membrane thickness than the PP (M2) membrane, even though the latter shows a $20 \%$ increase in the porosity when compared to the PTFE (M3) membrane. A maximum flux of $88.8 \mathrm{~kg} / \mathrm{m}^{2} \mathrm{~h}$ was obtained at $80{ }^{\circ} \mathrm{C}$ and $20^{\circ} \mathrm{C}$ (feed and permeate inlet temperatures, respectively) using the PTFE (M3) membrane.

The fluxes obtained by commercial membranes were compared to the performance of a hydrophobic membrane made of fluorinated polytriazole synthesized in the laboratory and fabricated by an electrospinning method with an average fiber diameter of $100 \mathrm{~nm}$ and pore size higher than $1 \mu \mathrm{m}$ (Table 2) [36]. Under the same conditions, PP (M2) and PTFE (M1) commercial membranes gave a water vapor flux $12 \%$ and $27 \%$ lower than that obtained by the high performance locally fabricated electrospun membrane, respectively, as shown in Figure 5, 
but the latter had a lower salt rejection $(99.95 \%)$ than the commercial membranes $(99.99 \%)$. This is most probably due to the higher pore size of the electrospun membrane. On the other hand, the PTFE (M3) membrane showed a water vapor flux $4 \%$ higher than the electrospun membrane. The best commercial membrane providing the highest flux (PTFE M3) was tested using DI water in both feed and permeate sides. Results confirmed that feed water salinity does not significantly affect the MD flux as the latter decreased by only $5 \%$ when the DI feed water was replaced by real Red seawater having a salt concentration of 40.8 g/L (Fig. 5 and Table 3). Similar results have been reported by Adham et al. [17] where no significant decrease in flux was observed while varying the feed salt concentration from $1 \mathrm{~g} / \mathrm{L}$ to $100 \mathrm{~g} / \mathrm{L}$. In the MD process, the concentration polarization effect on flux is much less significant than the temperature polarization. These results are in agreement with the investigation on the effect of temperature and concentration polarization in MD carried out by Khayet (2011) [3], Edwie and Chung [37], and Martinez-Diez and Vazquez-Gonzalez (1999) [48].

\subsection{Scale-up issues}

The data obtained in bench scale operating conditions study does not reflect reality for larger modules, as is the case of most reported bench-scale works; therefore it is of limited use in scaling-up the MD process. The main reason for obtaining such high water vapor fluxes in bench scale studies is the operation at high $\Delta \mathrm{T}$ reaching $60{ }^{\circ} \mathrm{C}$ (e.g. feed /permeate of $80{ }^{\circ} \mathrm{C} / 20{ }^{\circ} \mathrm{C}$ ) with relatively high flow rates, which is not practically feasible in larger modules. The temperaturedrop (inlet - outlet) at the feed side and the temperature-increase (inlet - outlet) at the permeate side are expected to be significant in larger modules, especially in the lead membrane surface area (high feed temperature). In our bench scale module of a few centimeters length, the temperature-drop/increase (feed/permeate channels) at high feed and low coolant temperatures is about 3 to $4{ }^{\circ} \mathrm{C}$ at each side. In larger scale modules, these temperatures vary significantly from inlet to outlet reaching a 50\% drop/increase depending on the module length and flow rates of both streams (flow rates are varied to meet the mass and energy balances of the system), which is not the case, for example, in RO process where the pressure-drop (trans-membrane pressure is the driving force) does not exceed $1 \%$ in a pressure vessel of 6 elements ( 1 element has a length of $1 \mathrm{~m}$ and a membrane surface area of $36 \mathrm{~m}^{2}$ ), which maintain the applied pressure (driving force) sufficiently higher than the osmotic pressure in the last element. 
The most realistic scenario in a large scale MD module is presented in Figure 6, which is in agreement with several air gap membrane distillation (AGMD) pilot test studies and new single stage and multi stage module designs with heat recovery systems [10, 12, 14, 20, 22, 23]. In the case of DCMD, despite the higher flux the efficiency is lower as the thermal efficiency decreases with increasing $\Delta \mathrm{T}$ due to the high heat input required and low heat recovery [13] as well as the thermal conduction (from feed to permeate sides) and the latent heat of water evaporation [50, 51]. As shown in Figure 6 (top), $\Delta \mathrm{T}$ across the membrane is considered constant at approximately $7-12{ }^{\circ} \mathrm{C}$ (as an example we take here an average of $10{ }^{\circ} \mathrm{C}$ ) though that condensation could be achieved at lower $\Delta \mathrm{T}$ as it is the case in MSF (similar concept to MD) where $\Delta \mathrm{T}$ of condensation/evaporation is about $5^{\circ} \mathrm{C}$ only [50]. Despite a constant $\Delta \mathrm{T}$ throughout the module, the water vapor flux at the hot inlet side (coolant outlet) is much higher than that at the hot outlet (coolant inlet). In fact, this is due to the fast decrease in the feed temperature along the membrane due to evaporation which leads to a decrease of the vapor pressure at the feed outlet and an increase of the coolant temperature on the other side of the membrane resulting in reduced driving force $(\Delta \mathrm{P})$, hence much lower flux is obtained. The higher the feed inlet temperature, the higher is the water vapor pressure at constant $\Delta \mathrm{T}$. As shown in Figure 6 (bottom), at feed/permeate temperature of $70 / 60{ }^{\circ} \mathrm{C}\left(\Delta \mathrm{T}=10{ }^{\circ} \mathrm{C}\right)$, the water vapor flux is 14.2 $\mathrm{kg} / \mathrm{m}^{2} \mathrm{~h}$, corresponding to an average $\Delta \mathrm{P}$ of about $11 \mathrm{KPa}$, whereas at $40 / 30{ }^{\circ} \mathrm{C}\left(\Delta \mathrm{T}=10^{\circ} \mathrm{C}\right)$ the flux is almost half $\left(7.7 \mathrm{~kg} / \mathrm{m}^{2} \mathrm{~h}\right)$ of that obtained at the hot inlet side of the module, corresponding to a $\Delta \mathrm{P}$ of about $3 \mathrm{KPa}$ only. This provides an average flux throughout the module of about 11 $\mathrm{kg} / \mathrm{m}^{2} \mathrm{~h}$, which is much lower than the reported results in bench-scale studies. Comparable values of $\Delta \mathrm{P}$ derived from temperature profiles on both sides of the membrane surfaces were obtained by simulation [13]. The average water vapor flux for larger modules is expected to be lower in other configurations such as AGMD or MGMD [51]. Winters et al. [22], found a flux of slightly higher that $1 \mathrm{~kg} / \mathrm{m}^{2} \mathrm{~h}$ in an AGMD pilot unit with a 7-meter long module at $\Delta \mathrm{T}=10{ }^{\circ} \mathrm{C}$ (hot and cold inlet temperatures of $80{ }^{\circ} \mathrm{C}$ and $25^{\circ} \mathrm{C}$ ) and at feed flow rate of $200 \mathrm{~kg} / \mathrm{h}$. A more detailed explanation of large scale module operating parameters/conditions such as the optimum module length, feed and coolant flow rates, and residence time, was reported in our recent work [50].

Figure 6: Water vapor flux profile at constant $\Delta \mathrm{T}=10{ }^{\circ} \mathrm{C}$ (feed and coolant inlet temperatures ranging from $40-70{ }^{\circ} \mathrm{C}$ and $30-60{ }^{\circ} \mathrm{C}$, respectively). 


\subsection{MD permeate analysis}

The conductivity of permeate was monitored continuously during the process and $99.99 \%$ salt rejection was observed in all cases (taking into account the dilution effect). This infers that only water vapor passed through the membrane to the permeate side and no pore wetting was observed. This behavior can be attributed to the high hydrophobicity as well as the required pore size of each membrane.

A detailed feed and permeate water quality analysis was performed using advanced equipment in order to investigate the capability of the MD process in removing organic matter and volatile compounds as well as the important ions/molecules in seawater desalination application such as boron concentration in the permeate [52]. Table 3 shows the physical and chemical analyses of feed and permeate solutions. Results show that MD membranes were a total barrier for ions achieving more than $99.99 \%$ of salt removal (conductivity reduced from 61,400 $\mu \mathrm{s} / \mathrm{cm}$ to $8.5 \mu \mathrm{s} / \mathrm{cm}$ ) and $99.41 \%$ of boron removal (boron concentration reduced from $5.1 \mathrm{mg} / \mathrm{L}$ to $0.03 \mathrm{mg} / \mathrm{L}$ in the permeate), which cannot be achieved by RO membranes even with a second pass system [53-55]. Water turbidity and total organic carbon (TOC) were reduced from 0.96 NTU to $0.08 \mathrm{NTU}$ and $1.94 \mathrm{mg} / \mathrm{L}$ to $0.5 \mathrm{mg} / \mathrm{L}$, respectively. However, LC-OCD analysis results indicated traces of lower molecular weight neutral molecules $(300 \mathrm{ppb})$ were found in the permeate (transported with the water vapor molecules through the membrane structure). As a comparison with other thermal processes, the concentrations of lower molecular weight compounds are much lower in MSF product due to higher operating temperature and vacuum system in the MSF evaporators [56].

Table 3: Feed and permeate water analysis obtained by PTFE (M3) membrane.

\subsection{Membrane characterization after the DCMD process}

EDX spectroscopic analysis of the deposited material on the membrane surface is shown in Figure 7. It reveals that different forms of scales were present on the membrane surface mainly, calcium carbonate, barium sulfate and magnesium hydroxide, which are commonly observed in seawater desalination operation [54, 56-59]. This result suggests that detailed investigation of pretreatment in the MD process is required especially for raw seawater at high temperature. 
Some research results have already been reported on scaling issues in the MD process [60, 61]. Adham et al., [18] compared the performance of the MD process for raw seawater (Gulf) and MSF brine. They found a steady water vapor flux production while using the MSF brine whereas, a flux decline over time was observed while using raw seawater as a feed solution, which emphasizes the need of pretreatment for a better MD performance. The main reason of this result is that the MSF brine is already pretreated, mainly injection of acid and antiscalant for scaling control and deaeration and venting systems for non-condensable gases removal [53], although its salt concentration is higher than that of raw seawater. Our investigation showed that the water vapor flux declined slightly (4.5\%) in the first hour and then stabilized at the steady state for the remaining operational time (Figure 8). It was found that scaling occurred at the inlet surface of the membrane which is common in thermal processes due to high feed water temperature, contrary to RO systems where scaling occurs in the last element due to higher concentration polarization $[53,54]$.

Figure 7: EDX spectra of deposited scales after the DCMD process.

Figure 8: DCMD water vapor flux vs time at feed and permeate inlet temperatures of $60{ }^{\circ} \mathrm{C}$ and $20{ }^{\circ} \mathrm{C}$, respectively, and at constant feed and permeate flow rates of 1.5 LPM.

\section{Conclusions}

In this study, we have explored different membranes to investigate the performance of the DCMD process for desalting real Red Sea water under bench scale module operating conditions (high $\Delta \mathrm{T}$ throughout the module) and large scale module operating conditions (low $\Delta \mathrm{T}$ throughout the module). The flux performance of the commercial membranes was first tested under optimized bench scale operating conditions with $\Delta \mathrm{T}$ reaching $70{ }^{\circ} \mathrm{C}$, and then the membrane which provided the highest flux was investigated for longer operation under large scale module operating conditions (i.e., at low $\Delta \mathrm{T}$ throughout the module) in order to be closer to practical conditions (scale-up). Among different PTFE membranes, the one with larger pore size and higher hydrophobicity gave the highest water vapor flux of $88.8 \mathrm{~kg} / \mathrm{m}^{2} \mathrm{~h}$ (at feed and permeate inlet temperatures of $80{ }^{\circ} \mathrm{C}$ and $20{ }^{\circ} \mathrm{C}$, respectively) which is $30 \%$ higher than that 
produced by the membrane with comparatively smaller pore size and lower hydrophobicity under similar experimental conditions. PTFE and PP membranes with similar characteristics showed similar flux patterns. On the other hand, under the same conditions, the best commercial membrane, PTFE (M3), provided comparable flux to that of the first generation of a locally synthesized electrospun membrane made of fluorinated polytriazole material. In addition to the acceptable water vapor permeability, high salt rejection (99.99\%) and boron rejection (99.41\%) were achieved with all membranes, suggesting that some of the factors limiting the MD process scale-up might also be related to module design and process engineering (with efficient heat recovery). On the other hand, under longer term operation, traces of lower molecular weight neutral molecules ( $300 \mathrm{ppb}$ ) were found in the permeate and membrane scaling was observed, suggesting the necessity of investigating pretreatment in the MD process. Also, it was confirmed that feed water salinity does not significantly affect water vapor flux. An increase in flux of only $5 \%$ was observed when replacing Red Sea water by DI water as feed. The concentration polarization effect on flux is much less significant than temperature polarization. At low and constant $\Delta \mathrm{T}$ of $10{ }^{\circ} \mathrm{C}$ throughout the module (large scale module operating conditions) and under similar feed and coolant inlet temperatures (Figure 6), the PTFE (M3) membrane gave an average flux of $11 \mathrm{~kg} / \mathrm{m}^{2} \mathrm{~h}$ (eight times lower than that of the bench scale module), which is still sufficiently attractive to scale-up the MD process especially for niche applications when conventional processes are not technically and economically feasible (e.g., treating high salinity feeds).

\section{Nomenclature}

\begin{tabular}{|c|c|c|}
\hline$A$ & $=$ & Effective membrane surface area $\left(\mathrm{m}^{2}\right)$ \\
\hline$C_{f}$ & $=$ & Feed solution concentration $(\mu \mathrm{S} / \mathrm{cm})$ \\
\hline$C_{p}$ & $=$ & Permeate solution concentration $(\mu \mathrm{S} / \mathrm{cm})$ \\
\hline$J v$ & $=$ & Water vapor flux $\left(\mathrm{kg} \cdot \mathrm{m}^{-2} \cdot \mathrm{h}^{-1}\right)$ \\
\hline$m_{w}$ & $=$ & Weight of the permeate $(\mathrm{kg})$ \\
\hline$S$ & $=$ & Surface area $\left(m^{2}\right)$ \\
\hline$S R$ & $=$ & Salt rejection (\%) \\
\hline
\end{tabular}




$\begin{array}{lll}t & = & \text { Time }(h) \\ V_{m} & = & \text { Membrane volume }\left(\mathrm{m}^{3}\right) \\ V p & & \text { Pore volume }\left(\mathrm{m}^{3}\right) \\ V_{t} & = & \text { Geometric volume }\left(\mathrm{m}^{3}\right) \\ w_{1} & = & \text { Weight of the dry membrane }(\mathrm{kg}) \\ w_{2} & = & \text { Weight of the wet membrane }(\mathrm{kg})\end{array}$

\section{Greek Symbols}

$\begin{array}{lll}\delta & = & \text { Thickness }(\mathrm{m}) \\ \rho_{\text {liq }} & = & \text { Density of the wetting liquid }\left(\mathrm{Kg} / \mathrm{m}^{3}\right) \\ \tau & = & \text { Tortuosity } \\ \varepsilon & = & \text { Porosity }(\%)\end{array}$

\section{References}

[1] N. Ghaffour, The challenge of capacity building strategies and perspectives for desalination for sustainable water use in MENA, Desalination \& Water Treatment 5 (2009) 48-53.

[2] A. Alkhudhiri, N. Darwish, N. Hilal, Membrane distillation: A comprehensive review, Desalination 287 (2012) 2-18.

[3] M. Khayet, Membranes and theoretical modeling of membrane distillation: A review, Advances in Colloid and Interface Science 164 (2011) 56-88.

[4] G.A. Mannella, V. La Carruba, V. Brucato, Some features of polymeric membranes for water purification via membrane distillation, Journal of Applied Polymer Science 122 (2011) 3557-3563.

[5] H. Susanto, Towards practical implementations of membrane distil, Chemical Engineering and Processing: Process Intensification 50 (2011) 139-150.

[6] E. Curcio, E. Drioli, Membrane distillation and related operations - A review, Separation and Purification Reviews 34 (2005) 35-86. 
[7] M. Goosen, H. Mahmoudi, N. Ghaffour, Water desalination using geothermal energy, Energies 3 (2010) 1423-144.

[8] R. Sarbatly, C.-K. Chiam, Evaluation of geothermal energy in desalination by vacuum membrane Distillation, Applied Energy 112 (2013) 737-746.

[9] M.F.A. Goosen, H. Mahmoudi, N. Ghaffour, Today's and future challenges in applications of renewable energy technologies for desalination, accepted, Critical Reviews in Environmental Science \& Technology, Production tracking number: BEST 741313, ID: 741313, DOI:10.1080/10643389.2012.741313, 2012.

[10] E. Guillén-Burrieza, G. Zaragoza, S. Miralles-Cuevas, J. Blanco, Experimental evaluation of two pilot-scale membrane distillation modules used for solar desalination, Journal of Membrane Science 409-410 (2012) 264-275.

[11] N. Ghaffour, N.V. Reddy, M. Abu-Arabi, Technology Development and Application of Solar Energy in Desalination: MEDRC Contribution, Renewable and Sustainable Energy Reviews 15 (2011) 4410-4415.

[12] E. Guillén-Burrieza, J. Blanco, G. Zaragoza, D.-C. Alarcón, P. Palenzuela, M. Ibarra, W. Gernjak, Experimental analysis of an air gap membrane distillation solar desalination pilot system, Journal of Membrane Science 379 (2011) 386-396.

[13] Y.D. Kim, K. Thu, N. Ghaffour, K.C. Ng, Performance investigation of solar-assisted hollow fiber DCMD desalination system, Journal of Membrane Science 427 (2013) 345364.

[14] M.T. Ali, H.E.S. Fath, P.R. Armstrong, A comprehensive techno-economical review of indirect solar desalination, Renewable and Sustainable Energy Reviews 15 (2011) 41874199.

[15] K.W. Lawson, D.R. Lloyd, Membrane distillation, Journal of Membrane Science 124 (1997) 1-25.

[16] N. Ghaffour, T. Missimer, G.L. Amy, Combined desalination, water reuse and aquifer storage and recovery to meet water supply demands in the GCC/MENA region, Desalination \& Water Treatment 51 (2013) 38-43.

[17] K. Syed Amir Basha, Membrane distillation test for concentration of RO brine at WESSCO - Jeddah, IDA World Congress - Perth Convention and Exhibition Centre (PCEC), Perth, Western Australia September 4-9, 2011, Ref: IDAWC/PER11-351. 
[18] S. Adham, A. Hussain, J.M. Matar, R. Dores, A. Janson, Application of Membrane Distillation for desalting brines from thermal desalination plants, Desalination 314 (2013) 101-108.

[18] M.S. El-Bourawi, Z. Ding, R. Ma, M. Khayet, A framework for better understanding membrane distillation separation process, Journal of Membrane Science 285 (2006) 4-29.

[19] J. Koschikowski, M. Wieghaus, M. Rommel, Vicente Subiela Ortin, Baltasar Peñate Suarez, Juana Rosa Rodriguez, Experimental investigations on solar driven standalone membrane distillation systems for remote areas, Desalination 248 (2009) 125-131.

[20] Z. Kui, W. Heinzl, F. Bollen, G. Lange, Godart Van Gendt, C.F. Hoong (Eds.), Demonstrating solar-driven membrane distillation using novel memsys vacuum multieffect-membrane-distillation (V-MEMD) process, in: Singapore International Water Week, Suntec City-Singapore, 2011, pp. 23-25.

[21] F. Banat, N. Jwaied, M. Rommel, J. Koschikowski, M. Wieghaus, Desalination by a "compact SMADES" autonomous solar-powered membrane distillation unit, Desalination 217 (2007) 29-37.

[22] D. Winter, J. Koschikowski, M. Wieghaus, Desalination using membrane distillation: Experimental studies on full scale spiral wound modules, Journal of Membrane Science 375 (2011) 104-112.

[23] Z. Kui, W. Heinzl, F. Bollen, G. Lange, G. Van Gendt, A. Fane, Demonstrating solardriven membrane distillation using Memsys vacuum-multi-effect-membrane-distillation, World Congress/Perth Convention and Exhibition Centre (PCEC), Perth, Western Australia September 4-9, 2011 Ref: IDAWC/PER11-214.

[24] M.M. Teoh, S. Bonyadi, T.S. Chung, Investigation of different hollow fiber module designs for flux enhancement in the membrane distillation process, Journal of Membrane Science 311 (2008) 371-379.

[25] T.Y. Cath, V.D. Adama, A.E. Childress, Experimental study of distillation using direct contact membrane distillation: a new approach to flux enhancement, Journal of Membrane Science 228 (2004) 5-16.

[26] J. Phattaranawik, R. Jiraratananon, A.G. Fane, Effect of pore size distribution and air flux on mass transport in direct membrane distillation, Journal of Membrane Science 215 (2003) $75-85$. 
[27] M. Khayet, K.C. Khulbe, T. Matsuura, Characterization of membrane distillation by atomic force microscopy and estimation of their water vapor transfer coefficients in vacuum membrane distillation process, Journal of Membrane Science 238 (2004) 199-211.

[28] A.O. Imdakm, T. Matsuura, A Monte Carlo simulation model for membrane distillation processes: direct contact (MD), Journal of Membrane Science 237 (2004) 51-59.

[29] F.A. Banat, J. Simandl, Membrane distillation for dilute ethanol separation from aqueous streams, Journal of Membrane Science 163 (1999) 333-348.

[30] L. Francis, H. Maab, A. AlSaadi, S. Nunes, N. Ghaffour, G.L. Amy, Fabrication of Electrospun Nanofibrous Membranes for Membrane Distillation Application, Desalination \& Water Treatment 51 (2013) 1337-1343.

[31] J. Zhang, S. Gray, J.-D. Li, Modelling heat and mass transfers in DCMD using compressible membranes, Journal of Membrane Science 387-388 (2012) 7-16.

[32] J. Phattaranawik, R. Jiraratananon, A. G. Fane, Heat transport and membrane distillation coefficients in direct contact membrane distillation, Journal of Membrane Science 212 (2003) 177-193.

[33] J. Zhang, N. Dow, M. Duke, E. Ostarcevic, J.-D. Li, S. Gray, Identification of material and physical features of membrane distillation membranes for high performance desalination, Journal of Membrane Science 349 (2010) 295-303.

[34] J.-P. Mericq, S. Laborie, C. Cabassud, Vacuum membrane distillation of seawater reverse osmosis brines, Water Research 44 (2010) 5260-5273.

[35] S. Bandini, A. Saavedra, G.C. Sarti, Vacuum membrane distillation: experiments and modeling, AIChE Journal 43 (1997) 398-408.

[36] H. Maab, L. Francis, A. Al-Saadi, C. Aubry, N. Ghaffour, G.L. Amy and S.P. Nunes, Synthesis and fabrication of nanostructured hydrophobic polyazole membranes for lowenergy water recovery, Journal of Membrane Science 423-424 (2012) 11-19.

[37] F. Edwie, T.-S. Chung, Development of hollow fiber membranes for water and salt recovery from highly concentrated brine via direct contact membrane distillation and crystallization, Journal of Membrane Science 421-422 (2012) 111-123.

[38] L.D. Nghiem, F. Hildinger, F.I. Hai, T. Cath, Treatment of saline aqueous solutions using direct contact membrane distillation, Desalination and Water Treatment 32 (2011) 234241. 
[39] F. Banat, N. Jawied, M. Rommel, J. Koschikowski, M. Wieghaus, Performance evaluation of the "large SMADES" autonomous desalination solar-driven membrane distillation plane in Aqaba, Jordan, Desalination 217 (2007) 17-28.

[40] S.T. Hsu, K.T. Cheng, J.S. Chiou, Seawater desalination by direct contact membrane distillation, Desalination 143 (2002) 279-287.

[41] Y. Xu, B. Zhu, Y. Xu, Pilot test of Vacuum membrane distillation for seawater desalination on a ship, Desalination 186 (2006) 165-169.

[42] R.M. Rachman, N. Ghaffour, F. Waly, G.L. Amy, Assessment of silt Density Index (SDI) as fouling propensity parameter in Reverse Osmosis (RO) desalination systems, Desalination \& Water Treatment 51 (2013) 1091-1103.

[43] M. Thomaszewska. Membrane Distillation - Examples of Applications in Technology and Environmental Protection, Polish Journal of Environmental Studies, 9 (2000) 27-36.

[44] L. Palacio, P. Prádanos, J.I. Calvo, A. Hernández, Porosity measurements by a gas penetration method and other techniques applied to membrane characterization, Thin Solid Films 348 (1999) 22-29.

[45] J. Zhang, J.-D. Li, S. Gray, Effect of applied pressure on performance of PTFE membrane in DCMD, Journal of Membrane Science 369 (2011) 514-525.

[46] S. Adnan, M. Hoang, H. Wang, Z. Xie, Commercial PTFE membranes for membrane distillation application: Effect of microstructure and support material, Desalination 284 (2012) 297-308.

[47] E. Mendez, Sustainable desalination: Membrane distillation delivers greener clean water, Filtration and Separation, 49 (2012) 26-28.

[48] L. Martinez-Diez, M.I. Vazquez-Gonzalez, Temperature and concentration polarization in membrane distillation of aqueous salt solutions, Journal of Membrane Science 156 (1999) 265-273.

[49] A.G. Fane, R.W. Schofield, C.J.D. Fell, The efficient use of energy in membrane Distillation, Desalination 64 (1987) 231-243.

[50] A. Al-Saadi, N. Ghaffour, J.D. Li, S. Gray, L. Francis, H. Maab, S. Nunes, G. Amy, Modeling of air-gap membrane distillation process: A theoretical and experimental study, Journal of Membrane Science 445 (2013) 53-65. 
[51] L. Francis, N. Ghaffour, A. Alsaadi, G. Amy, Material gap membrane distillation: A new design for water vapor flux enhancement, Journal of Membrane Science 448 (2013) 240247.

[52] Y. Gacem, S. Taleb, A. Ramdani, S. Senadjki, N. Ghaffour, Physical and chemical assessment of MSF distillate and SWRO product for drinking purpose, Desalination 290 (2012) 107-114.

[53] N. Ghaffour, T.M. Missimer, G.L. Amy, Technical review and evaluation of the economics of water desalination: Current and future challenges for better water supply sustainability, Desalination 309 (2013) 197-207.

[54] K. Rahmawati, N. Ghaffour, C. Aubry, G.L. Amy, Boron removal efficiency from Red Sea water using different SWRO/BWRO membranes, Journal of Membrane Science 423-424 (2012) 522-529.

[55] N. Li and J. Li, Advanced membranes for water treatment, Advanced Membranes and Porous Materials Center Inauguration Technical Symposium, King Abdullah University of Science and Technology, March 2012.

[56] P.C. Mayan Kutty, A.A. Nomani, T.S. Thankachan, Analyses of water samples from Jeddah seawater RO/MSF plants for organic pollutants, Technical report No SWCC (RDC)-14, November 1991, pp. 182-219.

[57] C. Tzotzi, T. Pahiadaki, S.G. Yiantsios, A.J. Karabelas, N. Andritsos, A study of CaCO3 scale formation and inhibition in RO and NF membrane processes, Journal of membrane science 296 (2007) 171-184.

[58] W. Arras, N. Ghaffour, A. Hamou, Performance evaluation of BWRO desalination plant A case study, Desalination 235 (2009) 170-178.

[59] R. Sheikholeslami, M. Ng, Calcium sulfate precipitation in the 425 presence of nondominant calcium carbonate: Thermodynamics and kinetics, Industrial Engineering Chemistry Research 40 (2001) 3570.

[60] E. Curcio, X. Ji, G. Profio, E. Drioli, Membrane distillation operated at high seawater concentration factors: role of the membrane on $\mathrm{CaCO} 3$ scaling in presence of humic acid, Journal of Membrane Science 346 (2009) 263-269.

[61] M. Gryta, Fouling in direct contact membrane distillation process, Journal of Membrane Science 325 (2008) 383-394. 